\title{
Arterial hemorrhage due to a buried percutaneous endoscopic gastrostomy catheter
}
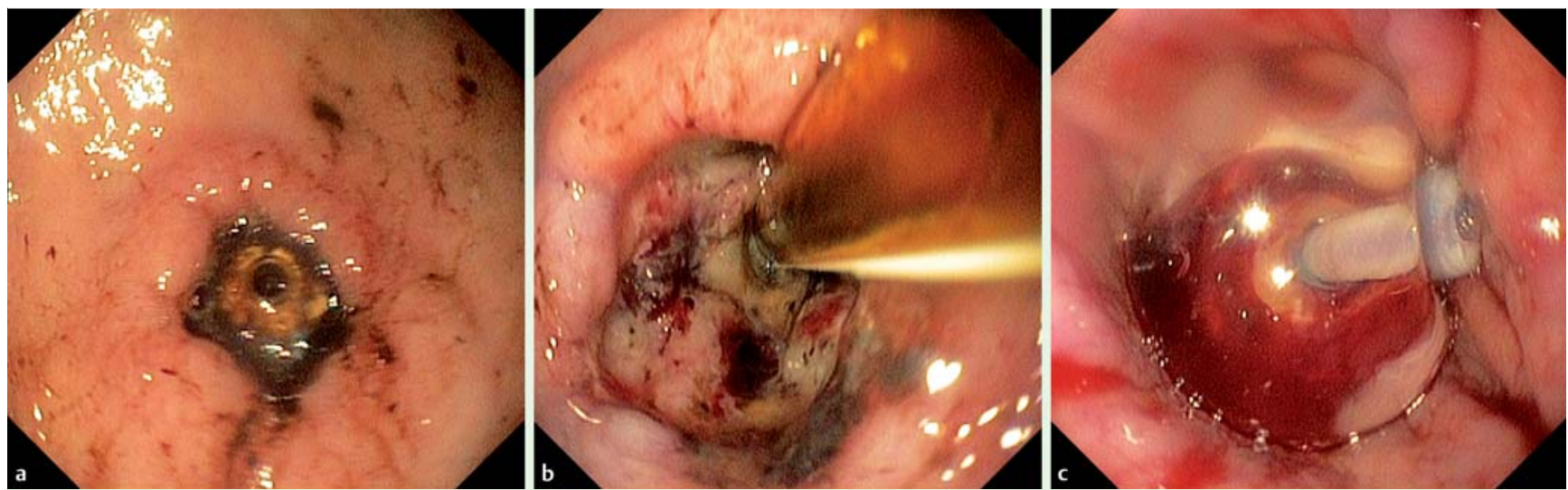

Fig. 1 Views during endoscopy in a 63-year old man with oropharyngeal carcinoma who had undergone placement of a percutaneous endoscopic gastrostomy (PEG) 1 month previously showing: a the partially overgrown bumper; $\mathbf{b}$ an ulcer with a pulsating large-caliber vessel at the 9-o'clock position; $\mathbf{c}$ the balloon-type catheter being used to tamponade the bleeding by forceful traction from the outside.

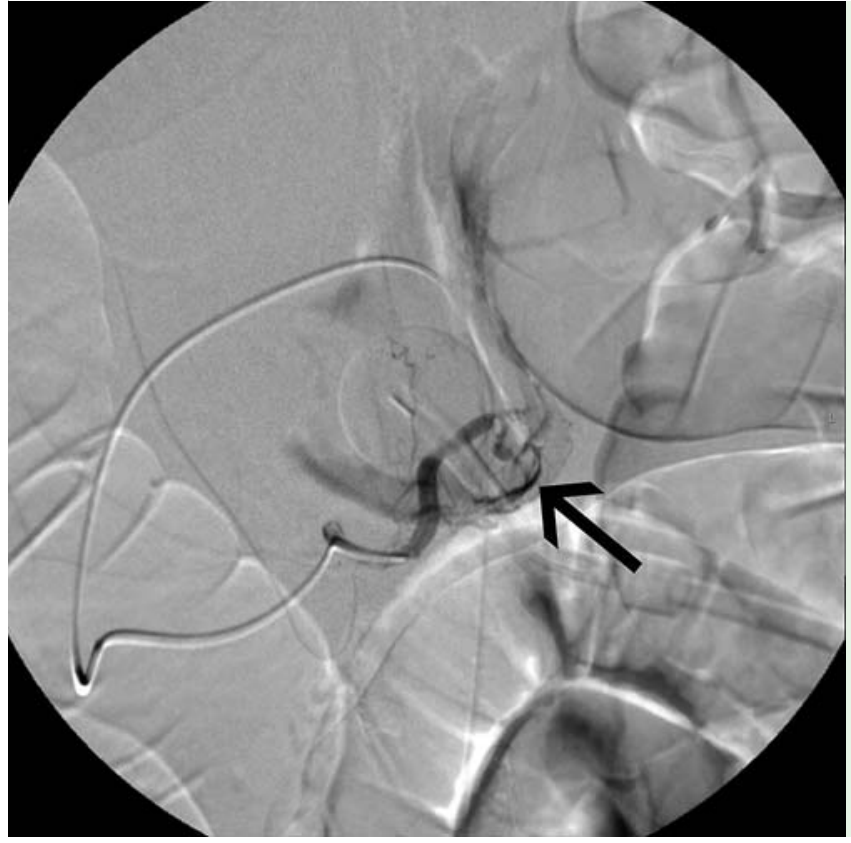

A 63-year old man underwent an emergency esophagogastroduodenoscopy because of hematemesis. He had undergone surgery 2 months earlier for a pT4aN3 oropharyngeal carcinoma. This had been followed 4 weeks later by placement of a percutaneous endoscopic gastrostomy (PEG) because of severe oropharyngeal dysphagia.

Endoscopy revealed a partially overgrown

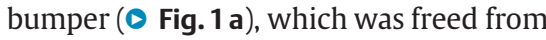
the stomach wall with careful pressure. This revealed an ulcer, with a pulsating
Fig. 2 Angiographic image showing massive contrast extravasation (arrow) from the right gastroepiploic artery.

large-caliber vessel at the 9-o'clock position ( Fig. 1 b). During the endoscopy, a massive arterial hemorrhage occurred originating from this vessel. In the absence of any endoscopic option to control the bleeding, the bumper-type PEG catheter was swiftly changed to a balloon-type catheter, which was used to tamponade the bleeding by forceful traction from the outside ( $\bullet$ Fig. 1 c).

We performed angiography and a catheter was advanced into the right gastroepiploic artery. When traction on the balloon catheter was decreased, massive contrast extravasation became visible from this artery ( Fig.2). Microcoils (Boston Scientific, Natick, Massachusetts, USA) were placed at the site of extravasation, which resulted in immediate cessation of the bleeding. After 1 day of clinical observation, the patient was discharged. He died 7 weeks later from progression of the cancer. In the meantime, the balloon catheter had been used for feeding without problems.

PEG-related complications can be severe and life threatening [1,2]. Arterial hemorrhage resulting from erosion of the internal bumper into the gastric wall (buried bumper) is rare [3]. In this case, we believed that the caliber of the artery was too large for successful application of a heater probe or conventional clips. We therefore immediately decided to insert a balloon-type catheter, with the aim of temporarily tamponading the vessel until a definitive treatment could be performed. We had incidentally used balloon traction to stop minor bleeding immediately after placement of the PEG. This method has not been described in severe arterial bleeding before.

Endoscopy_UCTN_Code_TTT_1AO_2AD

Competing interests: None 


\section{S. J. Van Weyenberg ${ }^{1}$, R. J. Lely ${ }^{2}$}

${ }^{1}$ Department of Gastroenterology and Hepatology, VU University Medical Center, Amsterdam, The Netherlands

2 Department of Radiology, VU University Medical Center, Amsterdam,

The Netherlands

\section{References}

1 Schulenberg E, Schüle S, Lehnert T. Emergency surgery for complications related to percutaneous endoscopic gastrostomy. Endoscopy 2010; 42: 872-874

2 Lee C, Im JP, Kim JW et al. Risk factors for complications and mortality of percutaneous endoscopic gastrostomy: a multicenter, retrospective study. Surg Endosc 2013: Epub ahead of print. DOI: $10.1007 /$ s00464013-2979-3

3 Anagnostopoulos GK, Kostopoulos P, Arvanitidis DM. Buried bumper syndrome with a fatal outcome, presenting early as gastrointestinal bleeding after percutaneous endoscopic gastrostomy placement. J Postgrad Med 2003; 49: 325-327

\section{Bibliography}

Dol http://dx.doi.org/

10.1055/s-0033-1344566

Endoscopy 2013; 45: E261-E262

(c) Georg Thieme Verlag KG

Stuttgart · New York

ISSN 0013-726X

\section{Corresponding author}

\section{S. J. Van Weyenberg, MD}

Department of Gastroenterology and Hepatology VU University Medical Center

De Boelelaan 1118

1081 HV Amsterdam

The Netherlands

Fax: +31-20-4440554

sjb.vanweyenberg@vumc.nl 